\title{
An Extended Polythiophene with Interesting Core Synthesis
}

\section{Key words}

conjugated polymers

base-induced cyclization

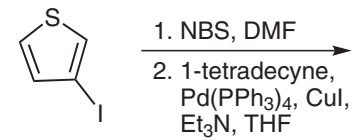<smiles>PC#Cc1ccsc1Br</smiles>

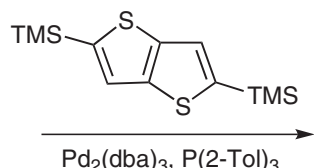

${ }_{1,2-\mathrm{Cl}_{2}} \mathrm{C}_{6} \mathrm{H}_{4}$

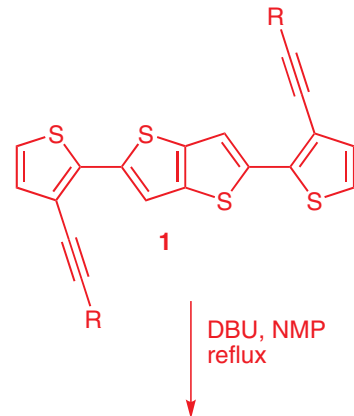

SYNFACTInth<smiles>[R]c1cc2cc(S(C)(=O)=O)sc2c2sc3c(sc4c5sc(C)cc5cc(P)c43)c12</smiles>
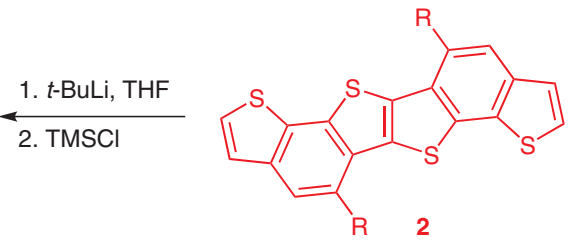<smiles>[2H]c1cc(Br)sc1Br</smiles><smiles>[R]c1cc(C(C)(C)C)sc1-c1cc2cc([R])c3c(sc4c5sc(-c6sc(C(C)(C)C)cc6[R])cc5cc([R])c43)c2s1</smiles>

$\mathrm{R}=\mathrm{C}_{14} \mathrm{H}_{29}$

Significance: A novel extended polythiophene derivative 4 was synthesized $\left(M_{n}=18 \mathrm{kDa}\right.$, $P D I=2.3)$. The key step in the monomer synthesis $(\mathbf{1} \rightarrow \mathbf{2})$ is accomplished in $78 \%$ yield by a novel base-induced cyclization.
Comment: The authors attempted to synthesize a homopolymer of the brominated analogue of $\mathbf{3}$ via a nickel-catalyzed dehalogenation, but a soluble polymer could not be obtained. The optical and electronic properties of $\mathbf{4}$ were found to be very similar to those of poly(3-hexylthiophene). 